Revista Brasileira de Meteorologia, v.27, n.2, 207 - 218, 2012

\title{
CONDIÇÕES TERMODINÂMICAS DE EVENTOS DE PRECIPITAÇÃO EXTREMA EM BELÉM- PA DURANTE A ESTAÇÃO CHUVOSA
}

\author{
JOÃO PAULO NARDIN TAVARES E MARIA AURORA SANTOS DA MOTA
}

\author{
Universidade Federal do Pará (UFPA), Programa de Pós-Graduação em Ciências Ambientais Belém, PA, \\ Brasil \\ jpnt25@gmail.com, aurora@ufpa.br
}

Recebido Outubro de 2010 - Aceito Outubro de 2011

\begin{abstract}
RESUMO
As condições termodinâmicas de uma região são muito importantes para o desenvolvimento da convecção úmida profunda, principalmente nas regiões tropicais. Portanto, o objetivo deste trabalho foi o de entender e caracterizar o papel das condições termodinâmicas da atmosfera durante os eventos de precipitações extremas na estação chuvosa, no período de 1987 a 2007, em Belém (PA). Os resultados mostram que as precipitações extremas, em sua maioria (56\%) apresentam um ambiente precursor com forte instabilidade, indicada pelos altos valores de CAPE (acima de $1000 \mathrm{~J} / \mathrm{kg}$ ) e valores significativos dos índices de instabilidade. Houve, contudo, eventos com baixos valores de CAPE na sondagem das 1200 UTC do dia do evento, mas valores maiores na véspera, o que indica que a chuva em questão pode ter começado na madrugada e ter perdurado por várias horas, atravessando a hora da sondagem, explicando a queda deste parâmetro. Os índices de instabilidade K, TT e LI apresentaram uma boa representação do ambiente, prognosticando as tempestades com chuvas fortes com índice de acerto de até $74 \%$, se levados em conta os eventos em que todos os índices apontavam os mesmos resultados e indicavam forte instabilidade. As condições termodinâmicas de forte instabilidade ajudam a promover, mas não são as únicas responsáveis pelas tempestades convectivas com precipitações extremas.
\end{abstract}

Palavras-chave: CAPE, Índices de Instabilidade, Tempestades severas, Precipitação extrema

\begin{abstract}
THERMODYNAMIC CONDITIONS OF EXTREME RAINFALL EVENTS IN BELÉM-PA, BRAZIL, DURING THE RAINY SEASON

The thermodynamic conditions from any region are very important to the development of the deep, moist convection, mainly in the tropical region. Therefore, the aim of this work was to understand and characterize the role of atmospheric thermodynamic conditions during extreme rainfall events in the rainy season, in Belém (PA, Brazil). The results show that the extreme rainfall, in their majority (56\%) present a pre-storm environment with strong instability, indicated by the CAPE high values (above $1000 \mathrm{~J} / \mathrm{kg}$ ) and meaningful values of the instability indexes. There was, however, events with low values of CAPE in the 1200 UTC sounding at the day of the event, but larger values in the day before, which indicates that the rain in question may have begun in the early hours and have last for several hours, crossing the time of the sounding, explaining the decrease of this parameter. The K, TT and LI instability indexes showed a close representation of the environment, predicting storms with heavy rainfall with $74 \%$ of correct identification, if taken into account the events on which all indexes showed the same indication of strong instability. Therefore, thermodynamic conditions of strong instability may lead to storms, but are not the only responsible factors for convective storms with extreme rainfall.
\end{abstract}

Keywords: CAPE, Instability indexes, Severe Weather, Extreme precipitation 


\section{INTRODUÇÃO}

Um dos fenômenos meteorológicos que mais afeta a sociedade é a tempestade convectiva com precipitações extremas. Do ponto de vista estatístico, eventos de precipitação intensa são aqueles, apesar de serem pouco numerosos, responsáveis por uma grande porcentagem do total de chuva em um dado período e região. Ou seja, são eventos com grande volume de precipitação em um único dia (Xavier et al, 2007).

O Município de Belém, capital do Estado do Pará $\left(01^{\mathrm{O}} 28^{\prime} \mathrm{S}, 048^{\mathrm{O}} 29^{\prime} \mathrm{W}\right)$, comporta aproximadamente 1,4 milhões de habitantes (IBGE, 2010) e se localiza numa das regiões mais chuvosas do leste da Amazônia (precipitação em torno de 2000 mm/ano) (Figueroa e Nobre, 1990). O clima de Belém é do tipo Af de acordo com o critério de Köppen (sempre úmido), com sazonalidade da estação chuvosa (meses de dezembro, janeiro, fevereiro, março, abril e maio - DJFMAM) (Figueroa e Nobre, 1990), que ocorre principalmente devido à migração latitudinal da Zona de Convergência Intertropical (ZCIT) nos meses de verão austral.

Os principais sistemas produtores de chuvas intensas, que podem se tornar eventos extremos, na estação chuvosa nessa região são: (i) a Zona de Convergência Intertropical (ZCIT); (ii) Linhas de Instabilidade; (iii) Convecção úmida profunda local e a interação entre alguns ou todos os elementos (Souza, 2006). Fenômenos climáticos de larga escala como a Oscilação Sul e o Gradiente Térmico Inter-hemisférico podem causar variabilidades na duração e intensidade da estação chuvosa na Amazônia (Marengo e Hastenrath, 1993). De qualquer forma, um sistema de tempo que produz intensa precipitação, sempre está relacionado à atividade convectiva e é o resultado da interação de mecanismos físicos de diferentes escalas (Rockwood e Maddox, 1988).

O fenômeno da convecção atmosférica domina as condições de tempo e clima da Amazônia. A convecção rasa (não precipitante, seguindo a divisão tradicional de parametrizações convectivas) e a convecção profunda (precipitante) estão entre os principais componentes do balanço de energia local. Além disso, a convecção precipitante é essencial no ramo atmosférico do ciclo hidrológico, influencia a dinâmica tropical de grande escala e exerce um papel fundamental no balanço de energia da circulação geral do planeta (Adams et al, 2009). Como na região tropical, a convecção profunda se desenvolve em uma área muito pequena na forma de células, o método da parcela pode ser empregado para avaliar a instabilidade da atmosfera e a formação de nuvens (Williams e Renno, 1993). Esse método deu origem aos parâmetros termodinâmicos, como a Energia Potencial Convectiva Disponível (CAPE) e os índices de instabilidade. Estes parâmetros mostram a estrutura termodinâmica vertical da atmosfera, de forma a caracterizar os processos físicos na geração da convecção e consequente precipitação.

A evolução do ambiente termodinâmico e sua relação com a convecção têm sido investigadas na Amazônia. Uma das mais importantes variáveis que moldam a estabilidade local do perfil termodinâmico é a CAPE. Ela desempenha um papel importante no acionamento e na intensidade da convecção. A CAPE, que é uma medida da flutuabilidade da parcela entre os níveis de convecção espontânea (NCE) e equilíbrio (NE), é controlada substancialmente pela evolução da camada limite, isto é, por mudanças nos fluxos de calor e umidade próximos à superfície (Betts, 1974).

Entretanto, a instabilidade termodinâmica não é o único fator que determina o surgimento da convecção profunda (Mota e Nobre, 2006). Portanto, pesquisar a ocorrência de tais fenômenos na Amazônia e como eles se desenvolvem é importante, haja visto a pouca quantidade de trabalhos que analisaram a CAPE e os índices de instabilidade, particularmente para a região. Então considerando essa necessidade é que foi desenvolvido este trabalho, que tem como objetivo geral caracterizar as condições termodinâmicas (CAPE e índices de instabilidade) associadas à formação e desenvolvimento de tempestades severas durante a estação chuvosa na região metropolitana de Belém.

\section{DADOS E METODOLOGIA}

\subsection{Dados de precipitação}

Para selecionar os eventos de precipitação intensa da estação chuvosa (DJFMAM) (Figueroa e Nobre, 1990), foi empregado o método dos decis (Xavier et al, 2007) nos dados de precipitação diária em Belém, provenientes da Embrapa Amazônia Oriental, do período de 1987 a 2007. O quinto decil corresponde à mediana, e o nono decil fornece os valores mais extremos da série (Spiegel, 1976). Fisicamente, o nono decil apresenta os casos mais raros de precipitação extrema, aqueles que, embora sejam em número muito reduzido, correspondem a $10 \%$ do total de eventos de chuva de toda a série. Assim, o valor limite da precipitação em Belém, para ser considerado severo, situa-se no nono decil, o que corresponde a $67,1 \mathrm{~mm} / \mathrm{dia}$.

Os dados de precipitação acumulada de 24 horas foram ajustados para coincidir com os dados da sondagem, pois a leitura da precipitação acumulada em 24 horas é feita sempre às 1200 UTC (09:00 hora local). Então o total observado corresponde à maioria da chuva ocorrida no dia anterior ao horário da observação. Enquanto que as radiossondagens são lançadas sempre no horário das 1200 UTC, desta maneira as condições termodinâmicas da sondagem não correspondem às observações feitas da precipitação. Haveria um erro na comparação dos dados, pois a sondagem forneceria os dados 
para um prognóstico, e a chuva seria do dia anterior à sondagem, caso fossem analisados os dados observados do mesmo dia. Para eliminar este erro, foi feito um ajuste, um deslocamento das datas da chuva, para coincidirem com a sondagem. Assim, a chuva registrada no dia 22 de março, por exemplo, foi comparada com os dados de sondagem do dia 21 de março.

\subsection{Descrição dos parâmetros termodinâmicos}

Para a análise das condições termodinâmicas, utilizaram-se dados das radiossondagens que foram realizadas diariamente em Belém, nos horários das 0000 e 1200 UTC, no período de 1987 a 2007, pelo Departamento de Controle do Espaço Aéreo de Belém - DTCEA-Be. Foram calculados a CAPE e os índices de instabilidade K, TT e LI, a partir das sondagens completas da véspera, do dia e do dia seguinte de cada evento. Com as sondagens das 1200 UTC do dia de cada evento, foi elaborado um padrão médio da estrutura vertical da troposfera e esse padrão foi classificado segundo os critérios de Betts (1974) e Aspliden (1976), que analisaram a estrutura vertical da troposfera em outras regiões tropicais e fizeram uma classificação das sondagens que pode servir de auxílio ao prognóstico de chuvas intensas. As sondagens das 1200 UTC foram escolhidas para esta classificação, bem como para o cálculo dos índices de instabilidade, porque nessa região, o horário preferencial de propagação de Perturbações Convectivas (PC) ocorre durante o fim de tarde (2100 UTC, i.e.,18:00 HL), com mínimo na manhã (1200 UTC, i.e., 09:00 HL). Para as PC de maior deslocamento, o horário preferencial é o meio da tarde (1800 UTC , i.e., 15:00 HL). (Barbosa et al, 2006).

\subsubsection{CAPE (Energia Potencial Convectiva Disponível)}

A CAPE é a medida da integral na vertical da flutuabilidade da parcela entre os níveis de convecção espontânea (NCE) e equilíbrio (NE). Fisicamente, a CAPE é a medida da energia cinética máxima, por unidade de massa de ar, proporcionada pela convecção de ar úmido proveniente da camada limite, assumindo-se ascensão pseudo-adiabática, e essa condição dá um limite superior para a velocidade vertical da corrente ascendente em uma nuvem convectiva (Ye et al, 1998).

Graficamente, é a área positiva do diagrama termodinâmico, que indica a quantidade de energia disponível para convecção. A área positiva existe quando a diferença entre a temperatura potencial equivalente da parcela $\left(\Theta_{\mathrm{ep}}\right)$ e a temperatura potencial equivalente saturada (ambiente) $\left(\Theta_{\text {es }}\right)$ for positiva. Isto significa que se a parcela de ar estiver mais quente do que o ambiente, a força de empuxo estará direcionada para cima.
A origem da parcela adotada neste trabalho fica no nível de $1000 \mathrm{hPa}$. A CAPE foi calculada através da Equação 1 (Emanuel, 1994, p.171):

$$
C A P E=\int_{N C E}^{N E} R d\left(T_{v p}-T_{v a}\right) d \ln p,
$$

onde: $\mathrm{T}_{v p}$ é a temperatura potencial equivalente da parcela, $\mathrm{T}_{V a}$ a temperatura potencial equivalente saturada (ambiente) e $\mathrm{Rd}$ a constante do gás para ar seco

O limite inferior da integral é o nível de convecção espontânea (NCE), nível no qual a parcela condensaria caso fosse levantada até este nível. A parcela, uma vez atingido o NCE continuaria em ascensão por um processo pseudoadiabático até que atingisse um nível de equilíbrio (NE), onde as temperaturas da parcela e do ambiente seriam a mesma, e o empuxo passa a ser direcionado para baixo. O NE é o limite superior da integral. A Tabela 1 apresenta de forma geral os valores de CAPE e as condições de instabilidade associadas, que podem ser tomadas como parâmetro de comparação com os resultados obtidos neste estudo.

Tabela 1 - Valores de CAPE.

\begin{tabular}{l|l} 
CAPE $(\mathrm{J} / \mathrm{kg})$ & Condições associadas \\
\hline $500 \leq \mathrm{CAPE}<1000$ & Convecção fraca \\
\hline $1000 \leq \mathrm{CAPE}<2500$ & Convecção moderada \\
\hline $\begin{array}{c}\text { CAPE }>2500 \\
\text { Convecção forte }\end{array}$ & Conve 1993$)$
\end{tabular}

Fonte: Bluestein (1993)

\subsection{2 Índice $\mathrm{K}$}

É usado para a estimativa do potencial de tempestades e de precipitação. É baseado na taxa de variação vertical da temperatura, no conteúdo de umidade na baixa troposfera e na extensão vertical da camada úmida. Este índice tende a capturar condições favoráveis à ocorrência de tempestades em ambientes úmidos em toda a troposfera, como é típico de ambientes tropicais, e apresentar valores relativamente baixos quando da intrusão de ar seco em níveis baixos a médios, aumentando a depressão do bulbo úmido em $700 \mathrm{hPa}$ (Nascimento, 2005).

$\mathrm{O}$ índice $\mathrm{K}$ pode ser calculado através da equação :

$$
\mathrm{K}=\left(\mathrm{T}_{850}-\mathrm{T}_{500}\right)+\mathrm{T}_{\mathrm{d} 850}-\left(\mathrm{T}_{700}-\mathrm{T}_{\mathrm{d} 700}\right)
$$

onde $\mathrm{T}$ é a temperatura do ar e $\mathrm{T}_{\mathrm{d}}$ é a temperatura do ponto de orvalho, ambas em graus Celsius.

Os números 850, 500 e 700 são os níveis nos quais devem ser obtidas as temperaturas. Quanto maior o índice K, maior a possibilidade de formação de nuvens Cumulunimbus.

$\mathrm{O}$ índice $\mathrm{K}$ é bastante útil na previsão de curto prazo (horas) e como é calculado rotineiramente nas sondagens das 1200 UTC no Aeroporto Internacional de Belém, auxilia a 
previsão de nuvens cumuliformes, trovoadas, pancadas de chuva e tempestades severas (informações utilizadas pelos pilotos para a segurança do voo) para o período da tarde, horário preferencial de desenvolvimento convectivo, como já discutido.

\subsection{3 Índice Total Totals (TT)}

O Índice TT combina três informações básicas: a taxa de variação vertical da temperatura de níveis médios, umidade no nível $850 \mathrm{hPa}$ e a temperatura no nível $500 \mathrm{hPa}$. De uma forma geral, valores de TT maiores do que 40 obtidos numa dada sondagem, indicam situações favoráveis a tempestades algumas horas mais tarde, e acima de 45 indicam chances de tempestades severas. Entretanto, analisar isoladamente o TT para a previsão convectiva não é adequado uma vez que um lapse rate alto em níveis médios pode levar a um TT alto, mesmo sem o fornecimento de umidade em baixos níveis (Nascimento, 2005).

O índice Total Totals é calculado através da Equação 3:

$$
\mathrm{TT}=\mathrm{T}_{850}+\mathrm{Td}_{850}-2 .\left(\mathrm{T}_{500}\right) \text {, }
$$

onde $\mathrm{T}_{850}$ e $\mathrm{T}_{500}$ são as temperaturas do ar no nível de $850 \mathrm{hPa}$, e $500 \mathrm{hPa}$, respectivamente;

$\mathrm{T}_{\mathrm{d} 850}$ é a temperatura do ponto de orvalho no nível de $850 \mathrm{hPa}$.

\subsection{4 Índice de Levantamento (LIFT INDEX, LI)}

O índice de instabilidade por levantamento é definido como:

$$
\mathrm{LI}=\mathrm{T}_{500}-\mathrm{T}_{500},
$$

onde, originalmente, $\mathrm{T}_{500}$ é a temperatura do ar ambiente em $500 \mathrm{hPa}$ e $\mathrm{T}_{500}$ ' é a temperatura de uma parcela de ar em 500 hPa (ambas em graus Celsius) após ascender - pela adiabática seca (pseudo-adiabática) antes (depois) da saturação - a partir da superfície, com a temperatura para o horário em que o perfil é obtido. Valores negativos de LI indicam condições instáveis. O índice LI é uma informação importante para analisar o grau de instabilidade atmosférica em microescala, especialmente quando combinado com a CAPE (Nascimento, 2005).

A Tabela 2 apresenta uma síntese dos índices de instabilidade, na concepção original, e as condições de tempo esperadas em até 12 horas. Estes valores e prognósticos são mais eficazes quando obtidos a partir da sondagem das 1200 UTC, como discutido anteriormente, devido ao ciclo do aquecimento diurno, e servem como parâmetro de comparação para os resultados obtidos. Dessa forma, os valores calculados a partir das sondagens das 1200 UTC do período de estudo serão comparados com as Tabelas 1 e 2, para se obter o prognóstico de tempo para curto prazo (até 12 horas).

\section{RESULTADOS}

\subsection{Caracterização dos eventos de precipitação extrema}

A Figura 1 apresenta a distribuição de frequência dos eventos de chuvas durante a estação chuvosa (DJFMAM), em Belém, no período de 1987 a 2007, segundo a classificação por decis (Xavier et al, 2007). Ocorreram 50 eventos extremos durante a estação chuvosa no período estudado.

Apesar de o limite inferior adotado ser $67,1 \mathrm{~mm}$, houve chuvas que totalizaram $200 \mathrm{~mm}$ em um só dia, o que corresponde a quase três vezes esse limite. Isso ocorre porque a evolução temporal, a frequência e a morfologia da convecção profunda podem variar enormemente, dependendo do regime convectivo. Alguns regimes experimentam sistemas convectivos organizados, enquanto outros experimentam um forte ciclo diurno de células convectivas não organizadas. Do ponto de vista climatológico, a chuva acumulada em 24 horas do dia 24 de abril de 2005, de 200,4 mm, foi a maior chuva nos últimos cento e dez anos $(1896$ - 2005) e trouxe muitos problemas à

Tabela 2 - Síntese dos valores dos índices de instabilidade K, TT e LI (para a sondagem das 1200 UTC) e condições de tempo esperadas no curto prazo (até 12 horas).

\begin{tabular}{l|l|l|l}
\hline Condições de tempo & $\mathrm{K}$ & $\mathrm{TT}$ & $\mathrm{LI}$ \\
\hline $\begin{array}{l}\text { Tempo estável, Pouco favorável à formação } \\
\text { de tempestades }\end{array}$ & $20 \leq \mathrm{K}<25$ & $\mathrm{~T}<40$ & $\mathrm{LI}>2$ \\
\hline $\begin{array}{l}\text { Instabilidade moderada, com possibilidade } \\
\text { de ocorrência de convecção rasa }\end{array}$ & $26 \leq \mathrm{K}<29$ & $41 \leq \mathrm{TT}<43$ & $0<\mathrm{LI}<2$ \\
\hline $\begin{array}{l}\text { Instabilidade forte, com possibilidade de } \\
\text { ocorrência de convecção profunda }\end{array}$ & $30 \leq \mathrm{K}<35$ & $44 \leq \mathrm{TT}<46$ & $-3,9<\mathrm{LI}<0$ \\
\hline $\begin{array}{l}\text { Instabilidade muito forte, com possibilidade } \\
\text { de tempestades severas com chuvas fortes } \\
\text { ascimento (2005). }\end{array}$ & $\mathrm{K}>36$ & $\mathrm{TT}>47$ & $\mathrm{LI}<-4$ \\
\end{tabular}

Fonte: Adaptado de Nascimento (2005) 


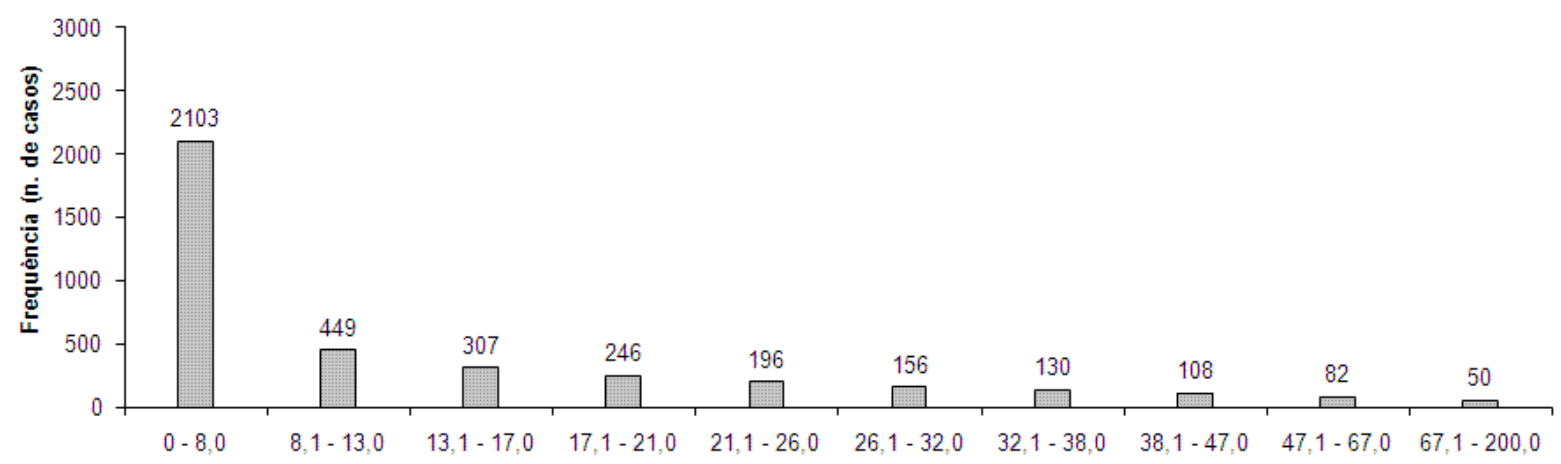

Figura 1 - Distribuição de frequência dos eventos de chuvas durante a estação chuvosa (DJFMAM) no período de 1987 a 2007.

população da cidade. Infelizmente, não ocorreram sondagens no mês de abril daquele ano para estudar o caso detalhadamente.

\subsection{Características termodinâmicas}

\subsubsection{Variabilidade da CAPE}

A Figura 2 apresenta a variabilidade da precipitação e CAPE, as colunas representam a chuva e a linha, a CAPE, de 39 eventos extremos ocorridos na estação chuvosa, no período de 1987 a 2007, em Belém. Dias em que não houve dados de radiossondagens, foram excluídos.

De uma maneira geral, a CAPE apresentou uma variabilidade muito grande, desde valores de aproximadamente $180 \mathrm{~J} / \mathrm{kg}$ até $4000 \mathrm{~J} / \mathrm{kg}$. Valores altos de CAPE (1400 J/kg - $3200 \mathrm{~J} / \mathrm{kg}$ ) foram encontrados por Rogash e Racy (2005), quando fizeram uma estatística das condições termodinâmicas de ambientes precursores de tornado e enchentes repentinas nos Estados Unidos, num período de 40 anos (1955-1995).

Em outras regiões da Amazônia (região Oeste, Rondônia), valores médios de CAPE de $1517 \mathrm{~J} / \mathrm{kg}$ são encontrados associados com desenvolvimento convectivo explosivo, com fortes correntes ascendentes, maior frequência de raios e chuvas mais fortes. Esta condição é encontrada sazonalmente, nos regimes de vento de leste próximo à superfície (Cifelli et al, 2004).

Diniz et al (2004) encontraram que a CAPE associada a tempestades severas durante o mês de abril de 1985 na região do aeroporto de Petrolina (PE), município este localizado também na região tropical equatorial, variava entre 715 e 3400 , resultados semelhantes aos encontrados neste estudo.

Em Belém, a convecção durante a estação chuvosa apresenta características de regimes tropicais marítimos, i.e., menor CAPE, correntes ascendentes mais fracas e reduzida atividade elétrica nas nuvens (Adams et al, 2009).

A instabilidade termodinâmica não é o único fator que determina o surgimento da convecção profunda. O cisalhamento do vento, a dinâmica de pequena e de grande escala, e as linhas de instabilidade podem exercer papeis fundamentais na ativação de elementos convectivos. Quase metade dos eventos (21 eventos) ocorreu nos meses de março e abril, meses de pico da atuação da Zona de Convergência Intertropical sobre a Costa Norte do Brasil, quando ocorre maior frequência de perturbações convectivas não-pontuais (atividade convectiva em escala sinótica associada às Linhas de Instabilidade, costeiras ou não) (Barbosa et al., 2006).

Entretanto, a existência da CAPE é fundamental para o desenvolvimento de tempestades. Sem CAPE, não há energia para o desenvolvimento das mesmas, e quanto maiores seus valores, maior é a possibilidade de formação de nuvens convectivas profundas em escala local, na ausência de forçantes de escala maior (Mota e Nobre, 2006).

Em 23\% dos casos (9), os máximos valores de CAPE ocorreram no dia de véspera e se mantiveram após o evento de precipitação. São os casos dos dias 11/03/88, 11/05/99, 15 e 18/04/00, 16/12/00, 05/04/03, 12/01/04, 02/03/06 e 02/12/07. Estes eventos podem ser chamados de Eventos de CAPE máxima. Por outro lado, foram observados 13 eventos (33\%) em que a CAPE se manteve baixa (menor do que $1000 \mathrm{~J} / \mathrm{kg}$ ) antes, durante e após o evento, eventos estes que podem ser chamados de Eventos de CAPE mínima: 11/01/88, 13/01/91, 09/02/92, 01/02/94, 06/03/94, 29/05/95, 06/03/96, 15/03/96, 23/03/96, 20/04/96, 19/03/97, 29/12/99 e 10/04/01. O restante (44\%) obteve maiores valores de CAPE antes da precipitação e menor depois (Tabela 3 e Figura 2).

As precipitações extremas costumam ocorrer em períodos de vários dias seguidos de chuva, devido a tempestades embutidas na Zona de Convergência Intertropical e/ou sistemas sinóticos. Isto talvez explique porque vários eventos são observados com baixos valores de CAPE na sondagem das 1200 UTC, que corresponde a 09:00 local. Nesses casos podia estar chovendo no momento da sondagem, ou ainda, a precipitação pode ter ocorrido oriunda de nuvens estratiformes, depois da dissipação dos Cumulonimbus (CBs). Por exemplo, nos dias 13 de janeiro 

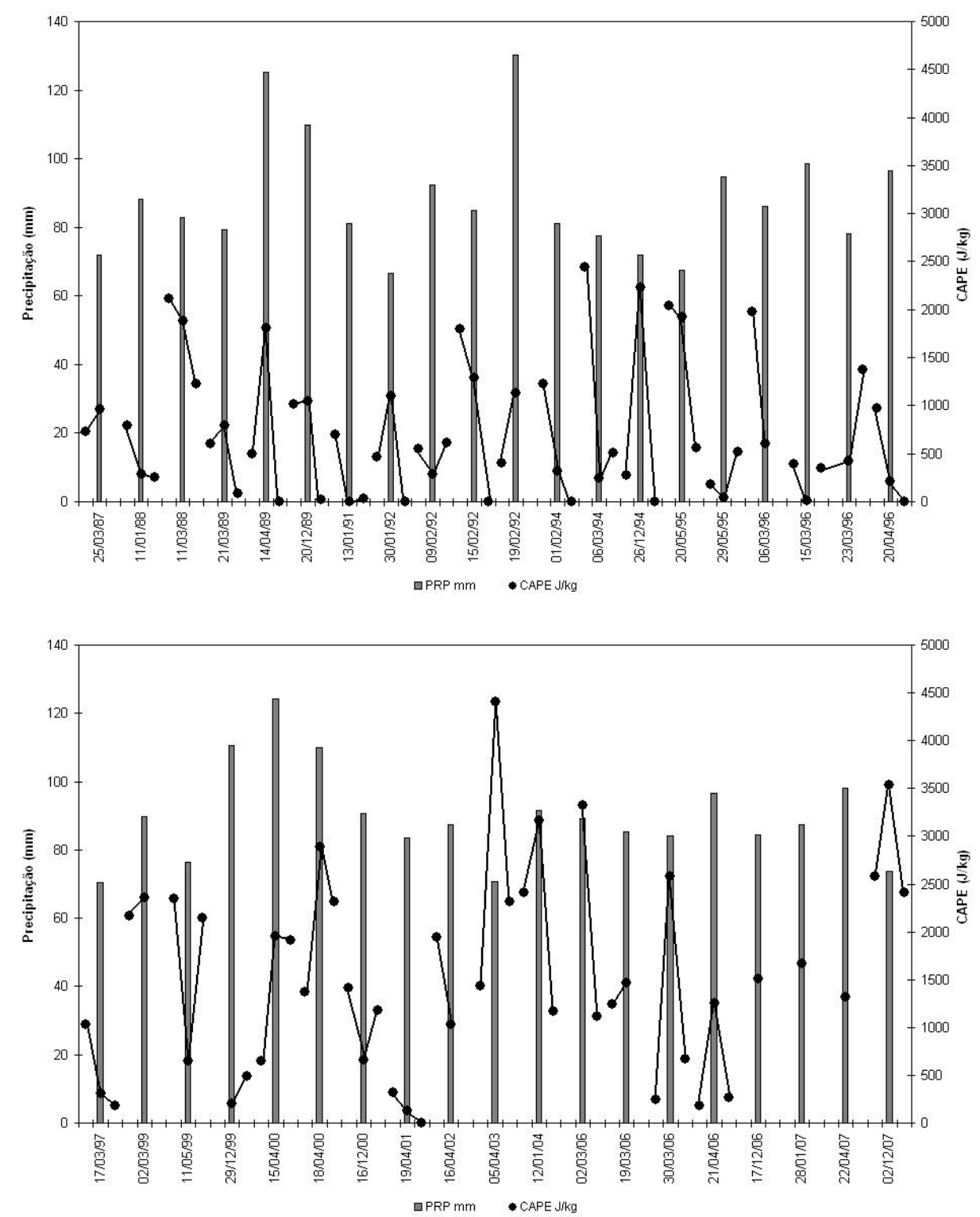

Figura 2 - Variabilidade da precipitação (colunas) e CAPE (linha), para os eventos extremos na estação chuvosa em Belém, período 1987 a 1996 (painel superior); 1997 a 2007 (painel inferior). Os pontos que aparecem entre as colunas representam a CAPE antes, durante e depois do dia do evento.

de 1991, e 15 de março de 1996, a CAPE encontrada foi 692,8 e 391,2 , respectivamente. As notícias em jornais locais informavam que a chuva começou de madrugada (do dia em questão) e choveu sem parar até o dia seguinte (Campos e Mota, 2009).

O processo de precipitação causa diminuição da CAPE através da intrusão de ar com baixa temperatura potencial equivalente na camada limite (Mota e Nobre, 2006). Por exemplo, o evento do dia 11 de março de 1988, dia em que houve uma tempestade com chuva forte $(82,8 \mathrm{~mm})$ e relâmpagos, que provocaram a perda de uma vida humana, a CAPE, antes da atividade convectiva máxima, era de $1883,2 \mathrm{~J} / \mathrm{kg}$ e na sondagem seguinte, após a chuva, a CAPE diminuiu para 1228,44 J/kg.
Como a CAPE necessária na região tropical para sustentação da convecção profunda, considerando as perdas dissipativas, tem de ser pelo menos $1000 \mathrm{~J} / \mathrm{kg}$ (Williams e Renno, 1993), os casos em que houve precipitação extrema com valores de CAPE inferiores a esse limite são os que chamam a atenção. Houve 18 casos com CAPE inferior a $1000 \mathrm{~J} / \mathrm{kg}$ na sondagem do ambiente precursor, o que corresponde a $46 \%$ do total de casos estudados: $25 / 03 / 87 ; 11 / 01 / 88 ; 21 / 03 / 89$; $14 / 04 / 89 ; 13 / 01 / 91 ; 30 / 01 / 92 ; 09 / 02 / 92 ; 19 / 02 / 92 ; 26 / 12 / 94$; $29 / 05 / 95 ; 15 / 03 / 96 ; 20 / 04 / 96 ; 29 / 12 / 99 ; 15 / 04 / 00 ; 19 / 04 / 01$; $30 / 03 / 06$ e 21/04/06. Esses eventos podem ter ocorrido devido à grande forçante dinâmica de grande escala, onde mesmo 
Tabela 3 - Valores de CAPE e dos Índices de instabilidade K, TT e LI das sondagens das 1200 UTC do dia de cada evento de precipitação extrema em Belém-PA (em negrito). Entre parênteses, valores das sondagens anteriores (véspera) e posteriores (dia seguinte) ao evento. Traços (---) significam ausência de dados.

\begin{tabular}{|c|c|c|c|c|c|}
\hline $\begin{array}{l}\text { Data do } \\
\text { Evento }\end{array}$ & $\begin{array}{l}\text { Precipitação } \\
\quad(\mathrm{mm})\end{array}$ & CAPE (J/kg) & Índice $\mathrm{K}$ & Índice TT & Índice LI \\
\hline $25 / 03 / 87$ & 71,8 & $964(725 /---)$ & $34(37 /---)$ & 40 (43/---) & $\mathbf{- 0 , 8}(-1,1 /---)$ \\
\hline $11 / 01 / 88$ & 88,3 & $282(791 / 251)$ & $21(21 / 34)$ & $42(37 / 41)$ & $\mathbf{- 1 , 8}(0,7 /-0,1)$ \\
\hline $11 / 03 / 88$ & 82,8 & $\mathbf{1 8 8 3}(2111 / 1228)$ & 39(39/34) & $46(46 / 43)$ & $\mathbf{- 2 , 9}(-3,0 /-2,4)$ \\
\hline $21 / 03 / 89$ & 79,4 & $791(601 / 80)$ & $34(34 / 31)$ & $45(45 / 42)$ & $\mathbf{- 2 , 0}(-2,5 /-0,8)$ \\
\hline $14 / 04 / 89$ & 125,3 & $1809(500 / 0)$ & $33(33 / 31)$ & $43(43 / 41)$ & $\mathbf{- 2 , 8}(-2,8 / 0,5)$ \\
\hline $20 / 12 / 89$ & 109,8 & 1043(1016/26) & $33(33 / 32)$ & $39(43 / 40)$ & $\mathbf{- 0 , 9}(-1,9 / 0,2)$ \\
\hline $13 / 01 / 91$ & 81,2 & о $(693 / 27)$ & $33(28 / 34)$ & $42(38 / 41)$ & $\mathbf{1 , 6}(-0,8 / 0,6)$ \\
\hline $30 / 01 / 92$ & 66,5 & $1103(465 / 0)$ & $38(35 / 30)$ & $43(44 / 45)$ & $\mathbf{- 0 , 2}(-0,9 /-0,5)$ \\
\hline $09 / 02 / 92$ & 92,4 & $282(553 / 611)$ & $38(31 / 38)$ & $44(38 / 44)$ & $\mathbf{- 0 , 8}(-0,1 /-0,8)$ \\
\hline $15 / 02 / 92$ & 85 & $1286(1798 / 0)$ & $34(32 / 32)$ & $43(43 / 43)$ & $\mathbf{- 2 , 2}(-2,4 /-0,4)$ \\
\hline $19 / 02 / 92$ & 130,2 & $1127(403 /---)$ & $36(36 /---)$ & $44(44 /---)$ & $-1,7(-2,0 /---)$ \\
\hline $01 / 02 / 94$ & 81,2 & $321(1226 / 0)$ & $33(24 / 33)$ & $42(38 / 42)$ & $\mathbf{1 , 3}(-1,8 / 1,3)$ \\
\hline $06 / 03 / 94$ & 77,6 & $241(2446 / 509)$ & $36(41 / 36)$ & $44(48 / 44)$ & $\mathbf{- 1 , 3}(-4,2 /-1,2)$ \\
\hline $26 / 12 / 94$ & 71,9 & $2232(272 / 0)$ & $27(36 / 30)$ & $44(44 / 41)$ & $\mathbf{- 3 , 5}(-1,0 / 0,7)$ \\
\hline $20 / 05 / 95$ & 67,5 & $1922(2043 / 562)$ & $30(36 / 30)$ & $43(44 / 43)$ & $\mathbf{- 1 , 7}(-3,0 /-1,7)$ \\
\hline $29 / 05 / 95$ & 94,7 & $42(181 / 514)$ & $32(27 / 39)$ & $43(40 / 53)$ & $\mathbf{- 1 , 7}(0,6 /-1,6)$ \\
\hline $06 / 03 / 96$ & 86,1 & $\mathbf{5 9 9}(1978 /---)$ & $36(36 /---)$ & $43(43 /---)$ & $\mathbf{- 2 , 3}(-2,3 /---)$ \\
\hline $15 / 03 / 96$ & 98,5 & $9(391 / 350)$ & $30(33 / 32)$ & $42(41 / 46)$ & $\mathbf{- 1 , 4}(-0,4 /-1,8)$ \\
\hline $23 / 03 / 96$ & 78 & $423(---/ 1376)$ & $34(---/ 29)$ & $45(---/ 43)$ & $-\mathbf{1 , 8}(---/-2,4)$ \\
\hline $20 / 04 / 96$ & 96,4 & $216(977 / 0)$ & $37(32 / 26)$ & $45(42 / 41)$ & $\mathbf{- 0 , 9}(-2,0 / 2,0)$ \\
\hline 17/03/97 & 70,3 & $306(1032 / 176)$ & $33(31 / 34)$ & $44(38 / 44)$ & $\mathbf{- 1 , 0}(-0,5 /-1,8)$ \\
\hline $02 / 03 / 99$ & 89,7 & 2353 (2165/---) & 39 (39/---) & $45(45 /---)$ & $\mathbf{- 2 , 8}(-2,8 /---)$ \\
\hline $11 / 05 / 99$ & 76,3 & $\mathbf{6 5 0}(2344 / 2144)$ & $35(38 / 38)$ & $43(47 / 47)$ & $\mathbf{- 1 , 8}(-4,4 /-4,7)$ \\
\hline $29 / 12 / 99$ & 110,6 & $201(---/ 404)$ & $33(---/ 33)$ & $42(---/ 42)$ & $\mathbf{0 , 2}(---/ 0,2)$ \\
\hline $15 / 04 / 00$ & 124,2 & $1958(647 / 1909)$ & $36(36 / 35)$ & $42(44 / 46)$ & $\mathbf{- 2 , 0}(-2,5 /-5,3)$ \\
\hline $18 / 04 / 00$ & 110,1 & $2883(1370 / 2318)$ & $38(35 / 39)$ & $45(46 / 47)$ & $\mathbf{- 2 , 9}(-4,0 /-5,2)$ \\
\hline $16 / 12 / 00$ & 90,6 & $663(1407 / 1178)$ & $33(34 / 37)$ & $41(45 / 49)$ & $\mathbf{- 0 , 3}(-3,7 /-4,7)$ \\
\hline 19/04/01 & 83,6 & $128(323 / 0)$ & $30(31 / 32)$ & $39(42 / 42)$ & $\mathbf{0 , 1}(-1,6 / 9,3)$ \\
\hline $16 / 04 / 02$ & 87,5 & $1033(1947 /---)$ & $36(29 /---)$ & $42(46 /---)$ & $-1,8(-5 /---)$ \\
\hline $05 / 04 / 03$ & 70,8 & $4402(1433 / 2312)$ & $36(35 / 39)$ & $45(46 / 46)$ & $\mathbf{- 3 , 2}(-3,8 /-4,8)$ \\
\hline $12 / 01 / 04$ & 91,5 & $3164(2409 / 1168)$ & $33(39 / 29)$ & $45(48 / 43)$ & $-2,0(-5,8 /-2,8)$ \\
\hline $02 / 03 / 06$ & 89,2 & $3322(---/ 1118)$ & $34(---/ 40)$ & $46(---/ 46)$ & $-\mathbf{1 , 8}(---/-3,0)$ \\
\hline $19 / 03 / 06$ & 85,3 & 1463 (1240/---) & $33(37 /---)$ & $42(43 /---)$ & $\mathbf{- 1 , 5}(-1,9 /---)$ \\
\hline $30 / 03 / 06$ & 84 & $2584(240 / 668)$ & $32(38 / 34)$ & $45(44 / 42)$ & $\mathbf{- 2 , 6}(-1,3 /-2,0)$ \\
\hline $21 / 04 / 06$ & 96,7 & $1252(180 / 269)$ & $31(37 / 33)$ & $43(43 / 43)$ & $\mathbf{- 1 , 6}(-1,0 /-1,6)$ \\
\hline $17 / 12 / 06$ & 84,3 & $1503(---/---)$ & $30(-------)$ & $42(---/---)$ & $-1,1(---/---)$ \\
\hline $28 / 01 / 07$ & 87,4 & $1664(---/---)$ & $33(---/---)$ & $45(---/---)$ & $-2,0(---/---)$ \\
\hline $22 / 04 / 07$ & 98,2 & $1319(---/---)$ & $34(---/---)$ & $45(---/---)$ & $-1,3(---/---)$ \\
\hline $02 / 12 / 07$ & 73,7 & $3535(2581 / 2408)$ & $31(42 / 23)$ & $46(48 / 46)$ & $-3,7(-5,5 /-5,0)$ \\
\hline
\end{tabular}

Fonte: Dados da pesquisa. 
havendo pequenos valores de CAPE, são suficientes para a formação da convecção profunda. Citando o evento extremo do dia 19 de fevereiro de 1992, houve $130 \mathrm{~mm}$ de chuva em pouco mais de 3 horas, o que acarretou em muitos prejuízos para a sociedade e duas mortes. Nesse evento, a CAPE encontrada na sondagem anterior ao evento foi de pouco mais de $500 \mathrm{~J} / \mathrm{kg}$ e no dia do evento foi de $1127 \mathrm{~J} / \mathrm{kg}$.

\subsubsection{Variabilidade dos índices de instabilidade}

Os índices de instabilidade também apresentaram grande variabilidade de um evento para outro, mas, em média, estiveram dentro dos limites definidos para instabilidade e chuva forte, já que durante a estação chuvosa na região tropical as temperaturas são sempre elevadas e há grande quantidade de umidade em toda a troposfera.

A variabilidade dos índices de instabilidade e CAPE durante os eventos pode ser observada na Tabela 3.

\subsubsection{1 Índices K E TT}

O Índice K médio das sondagens das 1200 UTC no dia do evento foi de aproximadamente 33,5. Entretanto, sabe-se que valores de $\mathrm{K}$ acima de 30 são considerados significativos, na América do Norte, e comumente são associados à alta probabilidade de ocorrência de tempestades com chuvas fortes.

Foram observados 25 casos (64\%) com índice K entre 30 e 35, o que indica Instabilidade forte, com possibilidade de ocorrência de convecção profunda, e 12 casos (31\%) com K > 36 (Instabilidade muito forte, com possibilidade de tempestades severas com chuvas fortes) (Tabela 3). Portanto, ao se notar que 95\% dos eventos onde o índice K prognosticava chuvas fortes e elas ocorreram, pode-se considerar o índice satisfatório para a previsão de tempo de curto prazo para a região.

Entretanto, no evento do dia 11 de janeiro de 1988, o índice $\mathrm{K}$ foi baixo $(21,3)$ e a CAPE também, não prognosticando chuvas fortes, mas a mesma ocorreu $(88,3 \mathrm{~mm})$. Provavelmente podia estar chovendo na hora da sondagem, o que estabiliza termodinamicamente o ambiente pelas correntes descendentes e chuva, diminuindo a temperatura em baixos níveis (Machado, 2000).

Mas isso não compromete a confiabilidade do índice, já que representa apenas um caso (2,5\% do total). Os 2,5\% restantes se resumem em outro único caso em que o índice $\mathrm{K}$ ficou entre 26 e 29 (Instabilidade moderada, com possibilidade de ocorrência de convecção rasa), mas na véspera da sondagem o índice era de 36.

$\mathrm{Se}$, mesmo durante a manhã, horário da sondagem, estivesse chovendo e o índice K apresentasse valores altos, pode significar que a atmosfera encontrava-se instável na camada que poderia sofrer convecção e desenvolver nuvens $\mathrm{Cb}$ algumas horas mais tarde.

Nos eventos de tempestades severas próximas ao aeroporto internacional em Petrolina (PE), em abril de 1985, os valores do índice $\mathrm{K}$ variaram entre 22 e 36,3 ; a maioria dos valores encontrados foi de 33 (Diniz et al, 2004), valores praticamente idênticos aos encontrados para Belém.

Já o Índice Total (TT) das sondagens das 1200 UTC, do dia de evento extremo, apresentou variação entre $38 \mathrm{e}$ 46, com média de 43, indicativo de instabilidade moderada com convecção rasa (Tabela 2). Cerca de 46\% (18 casos) apresentaram valores de TT entre 41 e 43 (Instabilidade moderada, com possibilidade de ocorrência de convecção rasa), e outros $46 \%$ ficaram com valores entre 44 e 46 (Instabilidade forte, com possibilidade de ocorrência de convecção profunda) (Tabela 3). Apenas dois eventos (5\%) tiveram TT abaixo de 40, foram os que ocorreram nos dias 20 de dezembro de 1989 $(\mathrm{TT}=39,3$; chuva $=109,8 \mathrm{~mm})$ e 19 de abril de $2001(\mathrm{TT}=$ 38,8 ; chuva $=83,6 \mathrm{~mm}$ ), mas nestes dois eventos o índice TT estava mais alto antes da ocorrência da chuva (seus valores eram de 43 e 42,3 ; respectivamente) e a chuva demorou mais de dez horas. Como discutido anteriormente, a chuva resfria a atmosfera, fazendo com que os valores dos parâmetros e índices de instabilidade termodinâmicos diminuam (Machado, 2000).

Portanto, apresentando ambiguidade como indicativo de instabilidade moderada e instabilidade forte ( $46 \%$ para cada caso), este índice não mostrou ser adequado para a previsão de tempestades severas e precipitações extremas para essa região, nessa época do ano.

A Figura 3 apresenta a variabilidade desses índices para cada evento. Na figura fica mais claro que a maioria dos valores do índice $\mathrm{K}$ está acima de 30 , que é o seu limite para instabilidade forte, com possibilidade de ocorrência de convecção profunda (de acordo com a concepção original), enquanto os valores do índice TT estão, na sua maioria, acima de 40, indicativo de instabilidade moderada.

\subsubsection{2 Índice LI}

Dos eventos extremos com valores do índice LI tomado à sondagem das 1200 UTC do dia do evento, $90 \%$ dos casos (35) foram indicativos de forte instabilidade (entre 0 e -3,9), enquanto os $10 \%$ restantes eram indicativos de estabilidade (valores positivos) (Tabela 3).

Além do mais, esses casos com valores positivos de LI apresentaram, também, baixos valores de CAPE na mesma sondagem, porém, todos eles tinham valores negativos de LI e maiores valores de CAPE na véspera do dia da chuva, como pode ser observado nas Figuras 2 e 4. Ou seja, no momento 

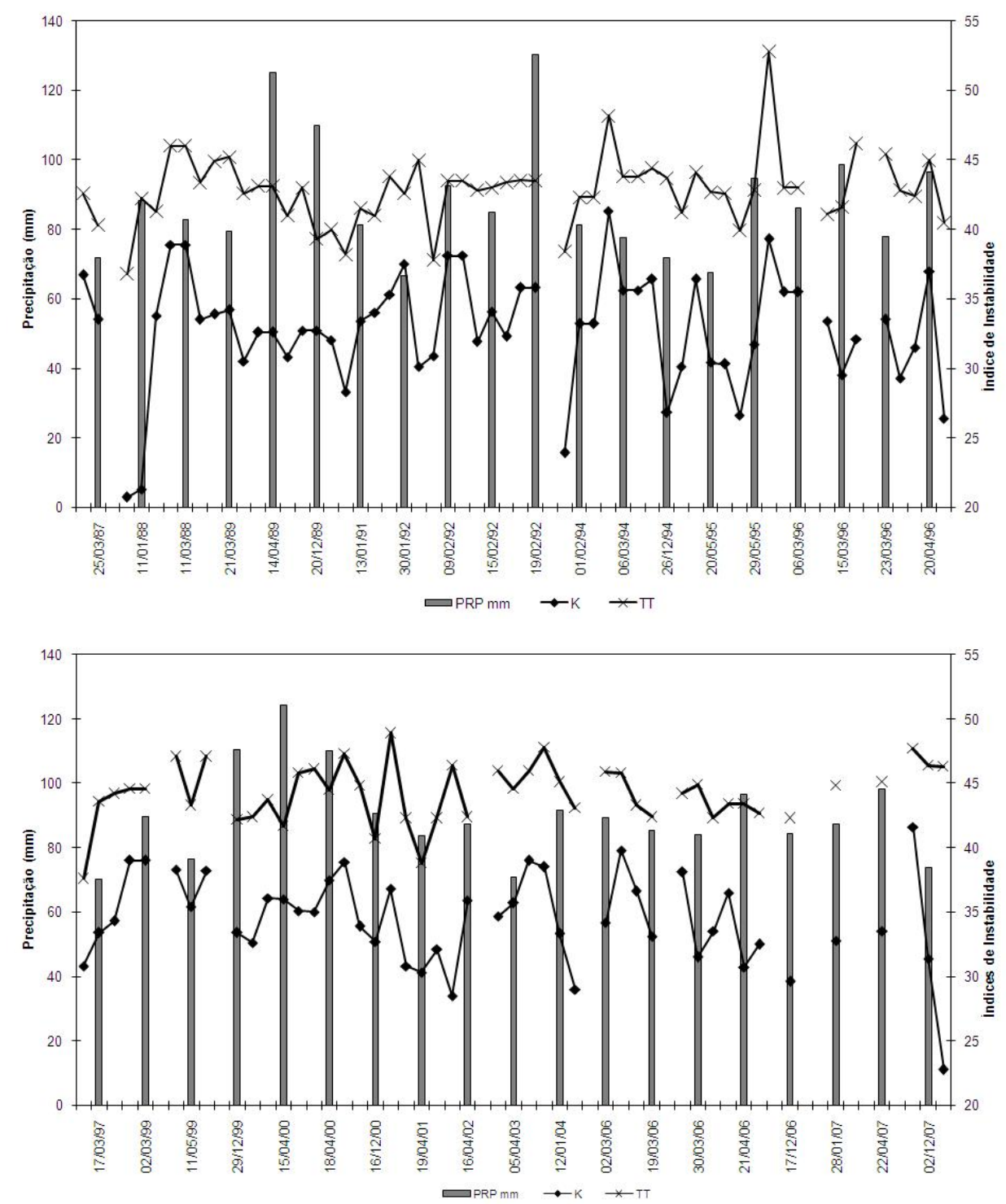

Figura 3 - Variabilidade da precipitação (colunas) e índices de instabilidade K e TT (linhas com marcadores), para os eventos extremos na estação chuvosa em Belém, período 1987 a 1996 (paine superior); 1997 a 2007 (painel inferior). Em volta de cada evento de precipitação podem ser observados três marcadores, que mostram os valores dos índices de instabilidade antes, durante e depois do evento.

da sondagem podia estar chovendo, mas o dia de véspera apresentava condições para formação da precipitação extrema. Por isso, o índice LI deve ser analisado juntamente com a CAPE para fins de prognóstico de tempo de curto prazo.

Os eventos com valores mais significativos de LI apresentaram, também, altos valores de CAPE, por exemplo, valores extremos, menores que -3 , foram encontrados nos dias 26/12/94 (chuva $=71,9 \mathrm{~mm}$ ); 05/04/2003 (chuva $=70,8 \mathrm{~mm}$ ) e 02/12/2007 (chuva $=73,7 \mathrm{~mm}$ ). Nesses eventos a forçante termodinâmica estava alta, a atmosfera encontrava-se bastante instável, o que já justifica o evento extremo do ponto de vista termodinâmico.
Entretanto, os menores valores de LI (tendendo a valores mais negativos) não correspondem exatamente às maiores precipitações. Apresentando $90 \%$ de acerto no prognóstico de forte instabilidade, o índice é considerado satisfatório para o prognóstico de tempo de curto prazo, desde que avaliado juntamente com a CAPE.

\subsubsection{Estrutura vertical média da troposfera de eventos de precipitação extrema}

A Figura 5 apresenta a média dos perfis verticais de temperatura potencial equivalente $\left(\Theta_{\mathrm{e}}\right)$ e temperatura potencial 

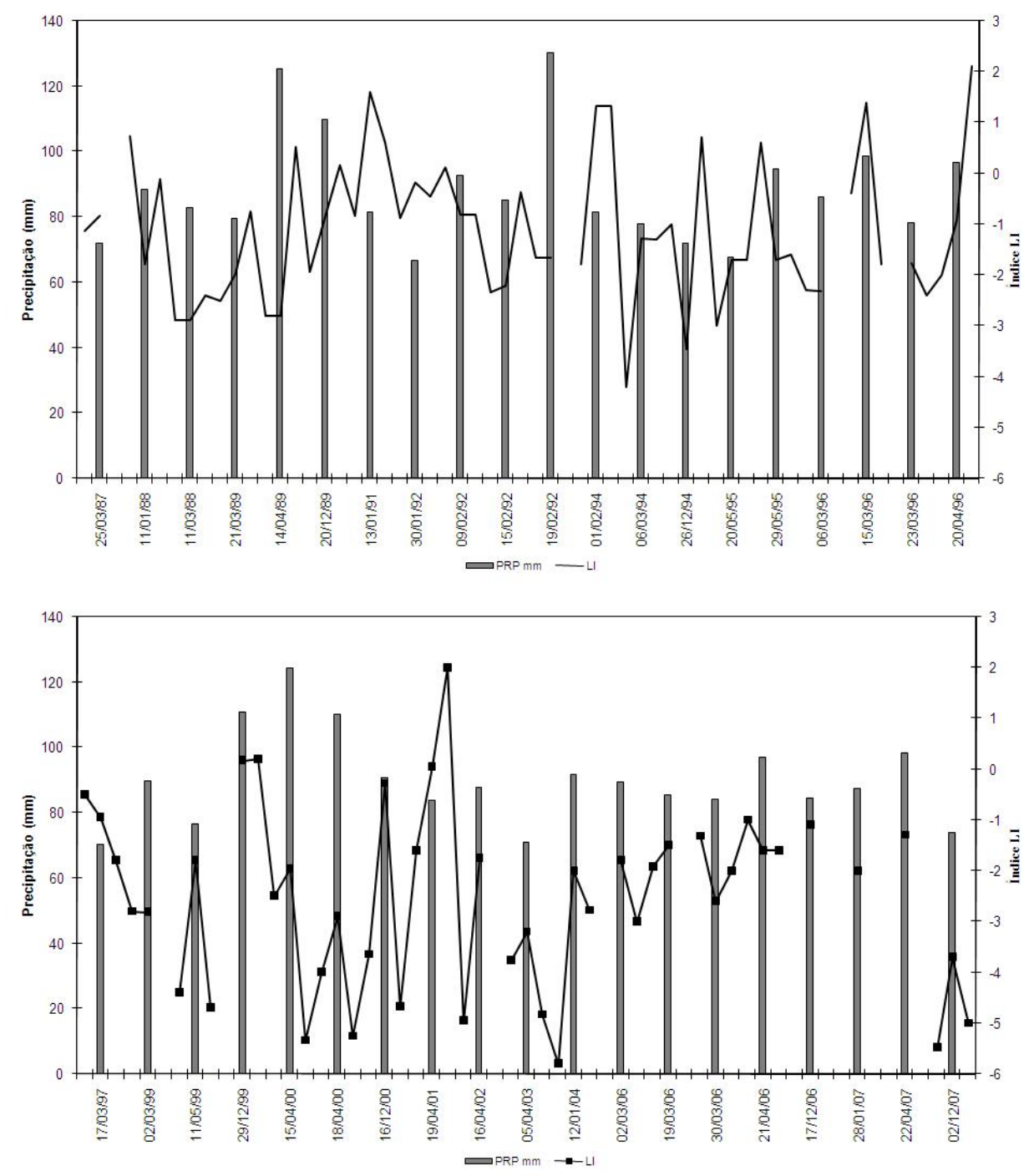

Figura 4 - Variabilidade da precipitação (colunas) e índice de instabilidade LI (linhas com marcadores), para os eventos extremos na estação chuvosa em Belém, período 1987 a 1996 (painel superior); 1997 a 2007 (painel inferior).

equivalente saturada $\left(\Theta_{\mathrm{es}}\right)$ das sondagens das 1200 UTC de eventos extremos na estação chuvosa em Belém, no período de 1987 a 2007. Na análise do perfil vertical médio verifica-se que o perfil atmosférico apresenta-se notadamente úmido, já que a maior diferença entre $\theta$ e e $\theta$ es é de $5 \mathrm{~K}$ desde a superfície até o nível de $700 \mathrm{hPa}$, e depois essa diferença diminui. O perfil apresenta NCE em aproximadamente 875 hPa e NE em 200 $\mathrm{hPa}$, conferindo uma grande área positiva $(\mathrm{CAPE}=1300 \mathrm{~J} / \mathrm{kg}$ ) se adotado a pseudo-adiabática com valor constante de $350 \mathrm{~K}$.

A "sondagem média" indica uma estrutura típica de ambientes atmosféricos precursores de tempestades severas, como Distúrbios, cuja característica principal é o grande conteúdo de umidade em toda a troposfera, com CAPE superior a $1000 \mathrm{~J} / \mathrm{kg}$.

A situação de Distúrbio sofre influência de sistemas de grande escala, que intensificam a atividade convectiva e podem gerar grandes precipitações sobre a área da sondagem (Betts, 1974). Por isso, as sondagens estão caracterizadas nos regimes convectivos III (Convecção Elevada). IV (Distúrbio), da mesma forma que ocorre em sondagens de eventos de precipitação forte em outras regiões tropicais (Betts, 1974) e VI (Convecção Severamente Desenvolvida) por possuir $\Theta_{\mathrm{e}}$ acima de $335 \mathrm{~K}$, ambientes que podem produzir tempestades severas com chuvas intensas (Aspliden, 1976).

\section{CONCLUSÕES}

A análise das condições termodinâmicas dos eventos de precipitação extrema da estação chuvosa (Dezembro a Junho) em Belém-PA no período de 1987 a 2007 mostrou que: 


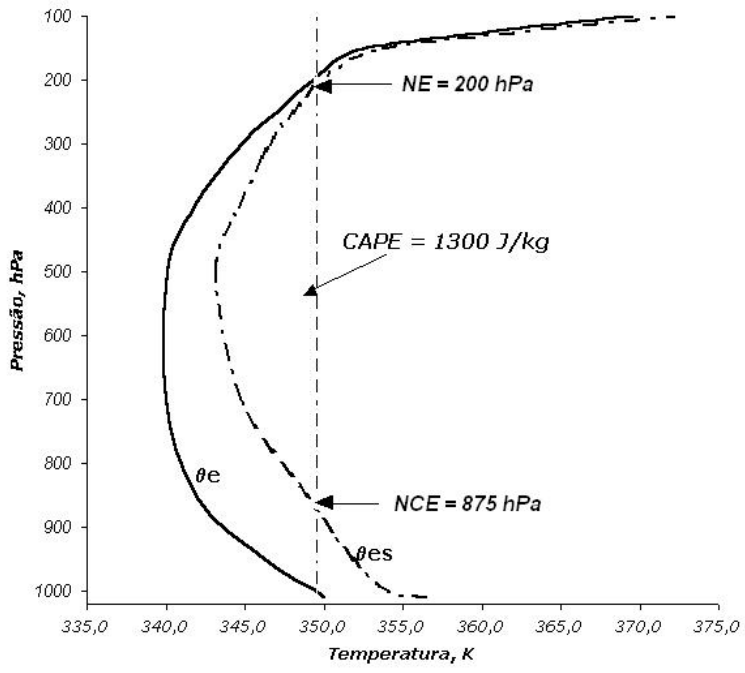

Figura 5 - Perfil vertical médio da temperatura potencial equivalente $\left(\Theta_{\mathrm{e}}\right)$ e temperatura potencial equivalente saturada $\left(\Theta_{\mathrm{es}}\right)$, para as sondagens de eventos extremos realizadas às 1200 UTC em Belém, na estação chuvosa, no período 1987- 2007. NCE = Nível de Convecção espontânea. NE = Nível de Equilíbrio.

(i) A convecção severa pode se desenvolver mesmo com baixos valores de CAPE. Sendo que 46,15\% dos eventos ocorreram com CAPE inferior a $1000 \mathrm{~J} / \mathrm{kg}$ (valor considerado limite para desenvolvimento da convecção profunda) antes do evento. Nesses casos, a convecção profunda e a precipitação extrema associada podem ter ocorrido devido a sistemas de meso e grande escala, que se sobrepuseram à escala local, e realimentam a convecção. Entretanto, a maioria dos casos $(53,85 \%)$ ocorreu com altos valores de CAPE, justificando os eventos extremos do ponto de vista termodinâmico. Esses altos valores de CAPE para eventos extremos estão de acordo com a literatura pesquisada, que mostra também altos valores de CAPE associados a tempestades severas em outras regiões do globo. Em 23\% dos casos (9), máximos valores de CAPE ocorrem no dia de véspera e durante, e se manteve após o evento de precipitação. São os eventos chamados de Eventos de CAPE máxima. Por outro lado, foram observados 13 eventos (33\%) em que a CAPE se mantém baixa (menor do que $1000 \mathrm{~J} / \mathrm{kg}$ ) antes, durante e após o evento, eventos estes que podem ser chamados Eventos de CAPE mínima.

(ii) $\mathrm{O}$ índice de instabilidade $\mathrm{K}$ das sondagens das 1200 UTC (09:00 HL) nos períodos de eventos extremos esteve sempre em torno de 30 , indicando $85 \%$ de possibilidade de formação de tempestades severas para o período da tarde ou início da noite, com exceção de apenas um caso. Então, o índice capturou as condições termodinâmicas favoráveis ao desenvolvimento de tempestades severas logo pela manhã e o evento ocorreu à tarde ou noite do mesmo dia. Desta forma, com $95 \%$ de acerto no prognóstico de chuvas fortes, o índice
K está adequado para a previsão de tempo de curto prazo para a região no período chuvoso, já que os mesmos valores foram encontrados para outras regiões tropicais equatoriais associados a chuvas fortes.

(iii) $\mathrm{O}$ índice TT foi ambíguo, com $46 \%$ dos casos fornecendo indicativo de instabilidade moderada e outros $46 \%$, instabilidade forte. Logo, não é um índice adequado à previsão de tempestades severas e precipitações extremas para a região, na estação chuvosa.

(iv) O índice LI das sondagens das 1200 UTC apresentou $90 \%$ de acerto no prognóstico de forte instabilidade, sendo considerado satisfatório, desde que avaliado juntamente com a CAPE, porque $10 \%$ dos casos tiveram LI positivo (indicativo de estabilidade) e baixíssimos valores de CAPE, entretanto, na véspera desses eventos, o índice LI era negativo e a CAPE apresentava maiores valores, indicando que podia estar chovendo no momento da sondagem.

(v) Ao serem considerados todos os eventos em que todas as condições termodinâmicas já apontavam um ambiente fortemente instável pela manhã, com altos valores de CAPE (acima de $1000 \mathrm{~J} / \mathrm{kg}$ ) e com resultados significativos de forte instabilidade em todos os índices, a estatística foi de 56\%.

(vi) Levando em conta apenas os índices de instabilidade, excetuando-se a CAPE, 74\% dos eventos tiveram respostas de forte instabilidade em todos os índices.

(vii) A estrutura vertical média dos dias de precipitação extrema apresentava grande conteúdo de umidade, CAPE acima de $1000 \mathrm{~J} / \mathrm{kg}$, valor limite para desenvolvimento da convecção úmida profunda e pôde ser classificada como convecção elevada ou distúrbio (Betts, 1974) e convecção severamente desenvolvida (Aspliden, 1976).

Logo, as condições termodinâmicas são necessárias, mas não são as únicas responsáveis pela formação da convecção úmida profunda com precipitações extremas na estação chuvosa na região de Belém. Os eventos extremos decorrem da atuação conjunta de vários sistemas, que realimentam a convecção. $\mathrm{O}$ fato de que eventos extremos ocorrem mesmo com uma pequena forçante termodinâmica, é motivação para estudos futuros acerca da interação entre a forçante dinâmica e a termodinâmica.

\section{AGRADECIMENTOS}

Os autores agradecem à Financiadora de Estudos e Projetos (FINEP) pelo financiamento do Projeto REMAM e concessão da bolsa; à Embrapa Amazônia Oriental, INMET e DTCEA-Be pela concessão dos dados; ao DSA-CPTEC-INPE pelas imagens de satélite gentilmente cedidas e à Biblioteca Setorial do Instituto de Geociências da UFPA pela ajuda na obtenção de artigos. 


\section{REFERÊNCIAS BIBLIOGRÁFICAS}

ADAMS, D.K.; SOUZA, E.P.; COSTA, A.R. Convecção úmida na Amazônia: Implicações para a modelagem numérica. Revista Brasileira de Meteorologia, v.24, n.2, p.168-178, 2009.

ASPLIDEN, C.I. A Classification of the structure of the Tropical Atmosphere and related energy fluxes. Journal Applied Meteorology, EUA, v. 15, n.7, p. 692-697, Jul. 1976.

BARBOSA, R.L., OYAMA, M.D., MACHADO, L.A.T. Climatologia das Perturbações convectivas iniciadas na costa norte do Brasil. Revista Brasileira de Meteorologia, v.21, n.1, 107-117, 2006.

BETTS, A.K. Thermodynamic classification of tropical convective sounding. Monthly Weather Review, EUA, v. 108, n. 1, p. 760-764, 1974.

BLUESTEIN, H. B. Observations and theory of weather systems. In: Synoptic - dynamic meteorology in midlatitudes. Oxford: Oxford University Press, 1993, v. 2, 595p.

CAMPOS, T. L. O. B.; MOTA. M. A. S. Histórico dos eventos meteorológicos extremos ocorridos em Belém-PA nos últimos 22 anos. In: Simpósio Internacional de Climatologia, III, Canela-RS, 2009. Anais... Brasília: SBMET, 2009.

CIFELLI, R. L. et al. An ensemble study of wet season convection in southwest Amazonia: Kinematics and implications for diabatic heating. Journal of Climate, $\mathrm{v}$ 17, p.4692-4707, 2004.

DINIZ, M.C., CORREIA, M.F., ARAGÃO, M.R.S. Convecção profunda no Submédio Rio São Francisco: Uma avaliação das condições atmosféricas na área do aeroporto de Petrolina-PE. Revista Brasileira de Meteorologia, v.19, n.3, p. 273-285, 2004

EMANUEL, K.A. Atmospheric convection. New York Oxford: University Press, 567 p. 1994.

FIGUEROA, S.N.; NOBRE, C.A. Precipitations distribution over Central and Western Tropical South America. Climanálise - Boletim de Monitoramento e Análise Climática, v. 5, n.6, p.36-45. 1990.

INSTITUTO BRASILEIRO DE GEOGRAFIAE ESTATÍSTICA - IBGE. Censo 2010. Disponível em: <www.ibge.gov.br>. Acesso em: 12 Jan. 2011.
MACHADO, L.A.T. The Amazon energy budget using the ABLE-2b and FluAmazon data. Journal of The Atmospheric Sciences, EUA, v. 57, n. 18, p.3131-3144, 2000.

MARENGO, J., HASTENRATH, S. Case studies of extreme climatic events in the Amazon basin. Journal of Climate, v.6, p.617-617, 1993 .

MOTA, M.A.S.; NOBRE, C.A. Relação da variabilidade da energia potencial convectiva disponível (CAPE) com a precipitação e a alta da Bolívia durante a campanha WetAMC/LBA. Revista Brasileira de Meteorologia, Brasil, v. 21, n. 3b, p. 344-355. 2006.

NASCIMENTO, E.L. Previsão de tempestades severas utilizando-se parâmetros convectivos e modelos de mesoescala: Uma estratégia operacional adotável no Brasil? Revista Brasileira de Meteorologia, v.20, n.1, p.121-140, 2005

ROCKWOOD, A.A.; MADDOX, R.A. Mesoscale and synoptic scale interactions leading to intense convection: The case of 7 June 1982. Weather and Forecasting, v. 3, n.1, p 51-68, 1988 .

ROGASH, J.A.; RACY, J. Some Meteorological Characteristics of Significant Tornado Events occurring in proximity to Flash Flooding. Weather and Forecasting, v. 17, n. 2, p.155-200, 2005.

SOUZA, E.B. Principais mecanismos dinâmicos associados à variabilidade da precipitação diária sobre a Amazônia Oriental durante a estação chuvosa. In: Congresso Brasileiro de Meteorologia, 14, Florianópolis-SC, 2006. Anais... Brasília: SBMET, 2006. CD-ROM.

SPIEGEL, M. R. Estatística. Coleção Schaum. São Paulo: McGraw-Hill do Brasil, 1976. 580p.

WILLIAMS, E.; RENNÓ, N.O. An Analysis of the conditional instability of the Tropical atmosphere. Monthly Weather Review, v. 121, n.1, p.21-36. 1993.

XAVIER, T.M.; XAVIER, A.F.S.; ALVES, J.M.B. Quantis e eventos extremos - aplicações em ciências da terra e ambientais. Fortaleza: RDS Editora, Livrarias Livro Técnico, 2007. 278p.

YE, B.; DEL GENIO, A.D.; LO, K.K.W. CAPE variations in the current climate and in a climate change. Journal of Climate, v. 11, n. 8, p.1997-2015. 1998. 